\title{
OS USOS SOCIAIS DO ENSINO DE GEOGRAFIA
}

\author{
THE SOCIAL USES OF GEOGRAPHY TEACHING IN BRAZIL
}

\section{LOS USOS SOCIALES DE LA ENSEÑNANZA DE LA GEOGRAFÍA EN BRASIL}

\author{
Roberto Marques \\ Professor Doutor da Faculdade de Educação da Universidade Federal do Rio de Janeiro (FE/UFRJ). \\ E-mail: robertogeofe@ufrj.br
}

\section{Resumo}

Este artigo pretende identificar algumas questões que foram colocadas para interseção geografia-educação, a partir dos processos de elaboração e implementação das recentes políticas de educação. Isso porque esses processos produzem tensões na zona de contato entre geografia e educação, em especial na vertente nomeada ensino de geografia. Para desenvolver a discussão, foram mobilizados os estudos de Pierre Bourdieu, especialmente o conceito de campo. Posteriormente, foi feito um esforço de caracterização e sistematização das abordagens que vêm sendo apresentadas, na interseção do campo da geografia com o campo da educação, em especial o que se entende por ensino de geografia. Com base nas contribuições de Bourdieu e na caracterização da vertente do ensino de geografia, o texto aponta movimentos e contradições desta e dos seus agentes nas relações com campos além da educação e da geografia, em especial o econômico e o político, no jogo das disputas e movimentos de consolidação e direcionamentos dentro dos campos e subcampos da geografia e da educação. Por fim, e com base nas discussões aqui trazidas, são apresentadas algumas perspectivas sobre os rumos e possibilidades de ação para o chamado ensino de geografia.

Palavras-Chave: Políticas educacionais, Ensino de geografia, Docência.

\section{Abstract}

This article aims to identify some issues that have been asked to intersect geographyeducation, from the processes of elaboration and implementation of recent education policies. This is because these processes produce tensions in the zone of contact between geography and education, especially in the so-called teaching of geography. To develop the discussion, Pierre Bourdieu's studies were mobilized, especially the concept of field. Later, an effort was made to characterize and systematize the approaches that have been presented, in the intersection of the field of geography with the field of education, especially what is meant by teaching geography. Based on Bourdieu's contributions and the characterization of the teaching aspect of geography, the text points out movements and contradictions of Bourdieu and its agents in relations with fields beyond education and geography, especially the economic and the political, in the game of disputes and consolidation movements and directions within the fields and subfields of geography and education. Finally, and on the basis of the discussions brought here, some perspectives are presented on the directions and possibilities of action for the so-called teaching of geography. 
Top of Form

Keywords: Policies of Education, teaching of geography, Teaching.

\section{Resúmen}

Este artículo pretende identificar algunas cuestiones que se han planteado para la intersección geografía-educación, a partir de los procesos de elaboración e implementación de las recientes políticas de educación. Esto se debe a que estos procesos producen tensiones en la zona de contacto entre geografía y educación, en particular en la vertiente nombrada enseñanza de geografía. Para desarrollar la discusión, se movilizaron los estudios de Pierre Bourdieu, especialmente el concepto de campo. Posteriormente, se realizó un esfuerzo de caracterización y sistematización de los enfoques que se vienen presentando, en la intersección del campo de la geografía con el campo de la educación, en particular lo que se entiende por enseñanza de geografía. Basándose en las contribuciones de Bourdieu y en la caracterización de la vertiente de la enseñanza de geografía, el texto señala movimientos y contradicciones de ésta y de sus agentes en las relaciones con campos además de la educación y la geografía, en particular el económico y el político, en el juego de las disputas y movimientos de consolidación y direccionamientos dentro de los campos y subcampos de la geografía y la educación. Por último, y sobre la base de las discusiones que se han presentado aquí, se presentan algunas perspectivas sobre las direcciones y posibilidades de acción para la llamada enseñanza de geografía.

Palabras clave: Políticas educativas, Enseñanza de geografía, docencia.

D D 


\section{Introdução}

Em 2015, foi lançada a versão preliminar da Base Nacional Comum Curricular (BNCC). Desde então e até o momento atual, em julho de 2019, outras versões foram apresentadas, criadas por processos diferenciados e aos sabores dos governos e ministérios pelos quais passamos. Tanto o anúncio da versão preliminar quanto todos os eventos e processos que foram desenhando o documento final mobilizaram uma parte considerável da comunidade acadêmica, em especial aqueles setores que se debruçam sobre as questões curriculares de disciplinas específicas ou mesmo os que trabalham sobre questões da educação em geral. Mas, não foram somente os agentes diretamente tocados pelos processos. Afinal, tratavase de discutir, propor e definir o que deve ser ensinado nas escolas da educação básica - o que se mostrou uma quase irresistível tentação, entre várias armadilhas.

O que chamo de "tentação" e de "armadilhas" são, em grande parte, os motivos deste texto. Elas dizem respeito aos modos como a área que articula geografia e escola se relaciona com o Estado, com as políticas públicas e com a categoria de professores da educação básica. O que cabe aqui é buscar identificar e compreender as dimensões políticas do que chamamos mais especificamente de ensino de geografia, bem como o lugar que essa denominação ocupa no contexto das reformas educacionais atuais. Para tal, primeiro é necessário observar as circunscrições da zona de contato entre a geografia e a educação; posteriormente, procuraremos situá-la no jogo das políticas educacionais do Brasil, em especial desde 2015 - quando foram divulgados os primeiros textos da BNCC - até o momento atual, em 2019. Finalmente, apresentarei um debate sobre as relações entre a universidade e a escola básica, atravessadas, hoje, por essas políticas de educação.

A necessidade da discussão que aqui será levantada está no reconhecimento da importância da escola como espaço de relações sociais e de produção de conhecimento. Um espaço que, ao contrário, vem sendo reforçado nas suas dimensões de controle, padronização e regulação, em detrimento da liberdade, diversidade e autonomia.

\section{Uma zona de contato entre a geografia e a educação}

A geografia é uma ciência academicamente organizada em áreas de domínios temáticos, de especificidades de abordagens ou por particularidades dos objetos. O debate sobre a natureza de cada uma dessas áreas remete invariavelmente às relações que as mesmas estabelecem com outras e com a própria geografia. Algumas vezes elas chegam a tomar corpo de campo científico-acadêmico, como é o caso da Region Science, que ganhou força 
a partir de meados dos anos 1950, na interface da economia regional com a geografia teorética e a ecologia, entre outras.

No caso da área de interface que comumente chamamos de ensino de geografia, podemos considerar em alguma media como um campo (ou subcampo) a partir da teoria de Pierre Bourdieu:

\begin{abstract}
"A noção de campo está aí para designar esse espaço relativamente autônomo, esse microcosmo dotado de suas leis próprias. Se, como o macrocosmo, ele é submetido a leis sociais, essas não são as mesmas. Se jamais escapa às imposições do macrocosmo, ele dispõe, com relação a este, de uma autonomia parcial mais ou menos acentuada". (Bourdieu, 2004, p. 20)
\end{abstract}

O exercício de tratar essa zona de contato como um campo ou subcampo ${ }^{1}$, abre a possibilidades de análise e discussão das relações internas, bem como desta interface com a sociedade, com o Estado e também com os demais campos com os quais se relaciona. Em outras palavras, é importante refletir sobre a construção da área - e para isso convém analisá-la a partir da perspectiva de campo.

O que identificamos como uma zona de contato da geografia com a educação tem recebido nomenclaturas diferentes. Ensino de Geografia, Geografia Escolar, Educação Geográfica e Geografia da Educação, são algumas denominações mais comuns, presentes em títulos de livros, eventos e trabalhos acadêmicos diversos. Porém, os nomes escolhidos são, também, as denominações dos diferentes entendimentos sobre recortes e sobre perspectivas de abordagens dentro da própria área. Em 2000, por exemplo, o Instituto Nacional de Estudos e Pesquisas Educacionais Anísio Teixeira (INEP), divulgou relatório intitulado Geografia da Educação Brasileira:

“[...] o INEP idealizou a Geografia da Educação Brasileira, publicação que reúne os principais indicadores educacionais do país, por regiões geográficas e unidades da federação. Trata-se de uma publicação que deverá assumir, a partir de agora, caráter permanente, voltando-se para a divulgação de séries estatísticas sobre a realidade do ensino". (INEP, 2000, p. 8)

Por sua vez, Júlio Takahiro Hato, na sua dissertação, intitulada “Geografia da Educação", sobre o próprio trabalho, assim escreveu:

"Com a interdisciplinaridade da Geografia Regional e a Educação Comparada, esta dissertação procura fundamentar esta análise e prospecção territorial da educação com base nas formas, funções e estruturas que produzem determinados espaços sociais ao longo de um processo histórico, resumindo-se num estudo de Geografia da Educação". (Hato, 2010, p. XII)

\footnotetext{
1 Uma proposta de recorte será apresentada mais adiante.
} 
Em ambos os casos, a interseção dos dois campos (educação e geografia) produz uma abordagem espacial ou geográfica da educação. A discussão sobre as possibilidades abertas por tal perspectiva mereceria um debate mais aprofundado, que não são objeto deste texto. O que importa, neste momento, é chamar atenção para a existência de um tratamento geográfico sobre a educação, ao mesmo tempo em que, na mesma perspectiva, trabalha-se com o que existe de geografia inerente à educação. De maneira mais objetiva, tomemos como exemplo a primeira citação - a geografia da educação, no relatório do INEP. Nela, o Ministério da Educação buscou identificar, no território nacional, a forma como estão distribuídas as políticas públicas, os indicadores utilizados nas aferições estatais sobre essas políticas, ou mesmo apresentar "uma visão abrangente sobre a realidade educacional do país" (INEP, 2000, p. 10), a partir de uma construção cartográfica da distribuição territorial dos indicadores populacionais, educacionais e de resultados das políticas públicas voltadas para a área. A educação é considerada, então, um objeto e a geografia é abordagem, arcabouço teórico-metodológico e concepção às quais o objeto está submetido. Ao mesmo tempo, nesse movimento reconhece-se que a educação tem em si uma dimensão geográfica.

Por outro caminho, o que vem sendo denominado como educação geográfica parte de uma perspectiva distinta sobre a interseção. Mais especificamente, a ideia de que a articulação da geografia com a educação, em alguma medida, pode ser tratada como "um amplo campo de conhecimento sobre as várias instâncias culturais envolvidas em processos de produção e representações da geografia" (Gonçalves, 2010). O que significa que se considera que existe tanto um conhecimento geográfico quanto um modo geográfico de pensar - e que ambos são ensinados. O ensinar e o educar, nesse caso, não se distinguem, uma vez que o centro desta abordagem está nos conhecimentos geográficos e nos modos geográficos de ver, representar e pensar o mundo, as coisas e os fenômenos.

A educação geográfica, por exemplo, estaria relacionada a elementos que vão desde os processos de ensino e aprendizagem até os sentidos de ensinar geografia, passando pelas contextualizações e especificidades dos conteúdos, dos lugares e dos sujeitos. Assim sendo, educação geográfica e ensino de geografia seriam dois nomes para um mesmo corpo. De fato, a geografia tratada como objeto do fenômeno educacional - por sua vez, entendido como aquilo que envolve os processos de ensinar e de prender - é o elemento central destas abordagens. Em linhas gerais, podemos dizer que do primeiro caso para o segundo (da geografia da educação para a educação geográfica) há uma mudança de posição dos campos de referência e dos objetos. No primeiro caso, a abordagem é geográfica sobre o objeto educação. No segundo, a geografia é o objeto a ser ensinado, ou seja, tratado preferencialmente a partir de referenciais do campo da educação. 
Mesmo dentro de recortes similares, há nuances que produzem algumas diferenciações. No caso, a chamada educação geográfica aparentemente se confunde com o ensino de geografia, ainda que sejam apresentados como perspectivas diferentes. Em elementos sutis, ainda que não sejam abordagens excludentes e opostas, as duas denominações apresentam algumas especificidades. A educação geográfica, por exemplo, estaria mais ligada aos sentidos e finalidades sociais da geografia trabalhada nas escolas:

\begin{abstract}
"A educação geográfica pode ser o caminho para educar para a cidadania por meio da geografia escolar. [...] A educação escolarizada traz consigo a discussão sobre conteúdos específicos e a dimensão pedagógica na medida em que a escola é o lugar de fazer a transmissão do conhecimento científico produzido pelas ciências". (Callai \& Moraes, 2017, p. 82)
\end{abstract}

Mais adiante, ainda identificada como um meio, a educação geográfica seria um dobramento do ensino de geografia:

\begin{abstract}
"Assim, a educação geográfica pode se estabelecer como um dos caminhos para estudar a geografia de modo que oportunize aos estudantes construírem as bases de conteúdos para a interpretação do mundo. [...] Se constitui, portanto, na perspectiva de acessar as ferramentas teóricas para entender o mundo e para as pessoas se entenderem como sujeitos nesse mundo, reconhecendo a espacialidade dos fenômenos espaciais". (Idem, p. 84)
\end{abstract}

Nos dois trechos, a escola seria "o lugar de fazer a transmissão do conhecimento científico produzido pelas ciências" - portanto, o conhecimento geográfico trabalhado na escola a ela circunscrito seria chamado de geografia escolar. A posição indicada da educação geográfica em relação à geografia que acontece na escola (chamada de geografia escolar), é semelhante àquela apresentada por Santos (2007), como ensino de geografia:

"Assim, o EG [Ensino de Geografia] é um espaço de conhecimento acadêmico
relativo às disciplinas que tratam mais diretamente da dimensão pedagógica
do pensamento geográfico. A produção acadêmica sobre essa rubrica não trata
de outra coisa que não seja a dimensão pedagógica do pensamento geográfico".
(Santos, 2007, p. 337)

Isso faz com que, mais uma vez, ensino de geografia e educação geográfica estejam em um mesmo recorte da zona de contato da educação e da geografia. Qual seja, a preocupação com a geografia a ser ensinada na educação básica, ainda que seja possível encontrar especificidades em cada uma dessas abordagens. Assim, podemos identificar quatro perspectivas de estudos e preocupações teóricas no entrelaçamento da educação com a geografia.

A primeira, em linhas gerais, na qual a educação é o objeto da investigação (geografia da educação); a segunda, que se preocupa com as finalidades e relações da geografia a ser 
ensinada e que, portanto, tem o conhecimento geográfico como objeto (educação geográfica); a terceira, que igualmente tem o conhecimento geográfico como objeto, mas que se dedica com maior interesse aos processos de ensino e aprendizagem, bem como nas escolhas metodológicas, didáticas e curriculares (ensino de geografia); e uma quarta, que diz respeito ao conhecimento geográfico circunscrito aos limites das escolas (geografia escolar ${ }^{2}$ ).

Todos esses recortes são apresentados aqui de maneira resumida e merecem um debate mais aprofundado, é verdade. Porém, o importante é apresentar brevemente algumas possibilidades de pesquisa, investigação e reflexão que o entrelaçamento da educação com a geografia permite. Possibilidades que vão muito além do ensino de, tão comum a diversas disciplinas (campos científicos e acadêmicos), que não raro reforçam princípios de uma hierarquização do conhecimento, configurando, assim, relações de poder dentro de um espaço social de produção de conhecimentos e de significados. É essa dimensão política do contato entre educação e geografia que emerge quando as atuais políticas de educação redefinem a ordem dos sistemas e redesenham as estruturas da educação brasileira.

Para entrarmos nesse debate, podemos pensar a zona de contato (geografia e educação) como um campo ou subcampo, a partir das proposições analíticas de Pierre Bourdieu.

\section{O ensino de geografia como um subcampo frágil}

Até o momento evitei ao máximo utilizar a nomenclatura campo, uma vez que o conceito define alguns atributos que agora serão apresentados. Preferi indicar a área como uma interface ou zona de contato entre dois campos - a geografia e a educação. Isso porque o primeiro passo é identificar as possibilidades de abordagens e os recortes de objetos que essa zona permite produzir. Porém, tanto as abordagens quanto os recortes não são necessariamente o resultado "natural" desse contato. Antes, são construções que reproduzem questões culturais, sociais, epistêmicas e políticas. Significa que não podemos supor que a geografia trabalhada pelos professores nas escolas estava simplesmente esperando para ser descoberta como objeto de pesquisa. Ela foi, na verdade, sendo incorporada aos campos como questão de pesquisa e foi sendo construída como problema a ser investigado, em contextos propícios para a sua emergência como objeto de investigação. Isso, se pensarmos como objeto de pesquisa científica; mas, podemos pensar, também, como objeto de disputas políticas e de representações.

\footnotetext{
A nomenclatura geografia escolar pode ser utilizada para se referir a recortes mais ampliados. Para os objetivos deste texto, apenas estão sendo indicadas algumas variedades de abordagens, sem a pretensão de fazer uma discussão mais densa sobre os conceitos e as denominações.
} 
Seja em qualquer dos casos, estamos diante de um espaço que tem buscado se definir (pelos sujeitos que nele atuam) como relativamente autônomo na construção de suas demandas, das suas lógicas e regras internas. Por outro lado, também há uma disputa pelo reconhecimento como espaço de especificidades entre dois campos razoavelmente reconhecidos e consolidados, independente do grau de autonomia que desfrutam, atualmente. A questão da autonomia diz respeito às formas como o campo se relaciona com as forças externas a ele, bem como à sua capacidade de produzir bases próprias do seu funcionamento.

Segundo Bourdieu, "quanto mais os campos científicos são autônomos, mais eles escapam às leis sociais externas" (Bourdieu, 2004, p. 30). Seja por qual denominação se considere (ensino de geografia, geografia escolar, etc.), tratar essa zona de contato como um campo seria atribuir a ela um nível de autonomia e reconhecimento que talvez seja precipitado supor. Por outro lado, reconhecendo que existe algum nível de demandas e ordem que podemos identificar como internas, cabe pensá-la como um subcampo de educação e geografia, por três motivos.

Primeiro, porque o encontro da geografia com a educação parece ter produzido mais uma área tributária de dois campos do que necessariamente um outro campo em diálogo com esses dois. A indefinição do objeto em bases próprias tornou, por exemplo, o ensino de geografia um tributário da geografia acadêmica, no qual a escola se converteu em objeto e o conhecimento de geografia trabalhado passou a ser uma proposta do subcampo. Ainda que sejam feitas investigações sobre as práticas docentes, o ponto de partida é invariavelmente a geografia acadêmica, seja assumindo de maneira explícita a hierarquização de saberes, seja escamoteada pela ênfase na docência como atividade externa, que se torna objeto.

Perguntas sobre o que ensinar, como ensinar e por que ensinar, perpassam o ensino de geografia. Todas elas, no entanto, partindo do subcampo, são pautadas em demandas da academia, transportadas às escolas e para os professores da educação básica. Por esse motivo, são frequentes as produções acadêmicas que dizem o que professores devem fazer, como devem ensinar, quais são as demandas da geografia para as escolas, qual geografia deve estar nas escolas e até mesmo os objetivos da geografia na educação básica para a sociedade.

Daí deriva o segundo motivo: as vinculações e hierarquias. Afinal, na indefinição de arcabouço teórico próprio, tende-se mais para um lado ou para o outro da filiação. Nesse ponto, cabe a pergunta: onde a interface geografia-e-educação se situa em relação à geografia e à educação? Tal questionamento nos ajuda a refletir sobre o caráter tributário que o subcampo tende a incorporar. Significa que ao tratarmos a geografia das escolas como um desdobramento ou tradução da geografia acadêmica, fazemos do ensino de

D 
ou da educação geográfica uma linha incompleta, dependente da base "geografia" para apontar a sua finalidade. Dependente, portanto, da geografia ou da educação, como campos legitimados para observar as escolas, para pensar e produzir sobre a educação básica. É o que acontece, por exemplo, quando as correntes do pensamento geográfico (acadêmico) são as referências para pensar a geografia das escolas, ignorando a possibilidade de existência de uma geografia que se produz a partir das demandas dos sujeitos das escolas.

Esses dois primeiros motivos, quando não resolvidos, produzem uma fragilidade teórica e política do subcampo - e daí ser muito difícil considerar como um campo, ainda que muitos deles também tenham suas tensões. É o caso da adesão a determinados referenciais teóricos ou metodológicos de outros campos, sem as devidas incorporações dos seus debates, das suas críticas, dos seus contextos de produção e usos. Um exemplo são as incorporações de termos como "letramento", "cidadania", ou a preocupação com o ensino dos "conceitos de geografia", sem a preocupação se os debates inerentes aos campos aos quais eles se relacionam são realmente compatíveis, incorporáveis, palpáveis, úteis e necessários aos debates do subcampo. Sem considerar, inclusive, em que medida e de que forma os diálogos interessam e são possíveis. O mesmo vale para as questões ligadas à avaliação educacional ou contextualizações e usos de concepções como o "construtivismo", spatial thinking (pensamento espacial), "competências e habilidades", "direitos de aprendizagem", entre outros. São conceitos, terminologias e concepções que desembarcam no subcampo muitas vezes sem questionamentos e carregadas pela autoridade das suas origens, simplesmente porque a falta de referenciais próprios proporciona a livre introdução e adaptação de referenciais de outros campos, de outras gramáticas e de outras demandas.

A situação torna-se mais delicada quando lembramos que o subcampo pode ser entendido como uma linha de aplicação de demandas ou objeto dos dois campos aos quais está diretamente relacionado. Basta vermos, por exemplo, como ainda se organizam alguns currículos de formação de professores, no Brasil, nos quais se expressa a ideia de que o licenciando é um derivado direto do geógrafo. $\mathrm{O}$ fato de ser um futuro professor é secundário, diante da necessidade primeira de ter a formação como geógrafo consolidada. No caso, a geografia acadêmica se impõe e estabelece uma relação de subalternização, reforçando a posição de subcampo, fazendo deste uma espécie de receptáculo das suas demandas, dos seus significados e dos seus referenciais.

Se "quanto mais autônomo for um campo, maior será o seu poder de refração e mais as imposições externas serão transfiguradas, a ponto, frequentemente, de se tornarem perfeitamente irreconhecíveis" (Bourdieu, 2004, p. 22), é justo considerarmos a zona de 
contato geografia-e-educação como um subcampo de ambas - da geografia e da educação. Porque, como foi descrito, a posição tributária e a relação de dependência com os campos de relação direta produzem uma condição que dificulta inclusive, tomadas de posição próprias, para além desses dois campos. Dito de outra maneira, muitas vezes as pressões sobre a autonomia são "resolvidas" a partir da geografia ou da educação, puramente, e não das especificidades do subcampo.

A questão da autonomia, então, nos remete ao terceiro e último motivo: os sujeitos e as posições. No caso do conhecimento geográfico tratado como objeto, temos duas categorias de sujeitos diretamente relacionadas a ele - os que trabalham com o conhecimento geográfico acadêmico e os que trabalham com o conhecimento geográfico nas escolas. Portanto, as duas categorias são: os reconhecidos pesquisadores da ciência geográfica e os professores da educação básica. Ora, se o ensino de geografia, na academia, não é identificado como uma área de produção de conhecimento geográfico, mas tão somente de conhecimento sobre as formas e contextos de articulação do conhecimento acadêmico de geografia com o conhecimento escolar de geografia, estabelece-se uma hierarquização com o subcampo dentro da própria geografia. Ao mesmo tempo, ao produzir sobre o conhecimento geográfico para e na escola, bem como sobre o trabalho docente dos conhecimentos de geografia, o subcampo tende a estabelecer, com tudo o que se remete à escola básica, uma relação igualmente hierarquizante - agora, desconsiderando a escola e os professores da educação básica como sujeitos do campo.

Assim, a distribuição do capital científico que determina as estruturas do subcampo, acabam sendo determinadas pelas apropriações que os agentes internos fazem de elementos simbólicos adquiridos de outros campos, especialmente os de referência direta (educação e geografia). Ou então, pelas capacidades dos agentes em se prontificar a dar respostas a demandas externas, ainda que consigam apresentá-las como demandas do subcampo.

Com isso, as pressões externas pelas quais o subcampo passa, tendem também a distanciá-lo dos professores da educação básica ou a reforçar suas posições como objetos. Um bom exemplo foram os embates recentes nas políticas de currículo, nas quais o foco foi o conteúdo de geografia (acadêmica) a ser defendido como importante ou "poderoso" para a sociedade e para as escolas, não importando os professores da educação básica como sujeitos nesse processo. O subcampo, nesse caso, assumiu um papel completamente tributário de uma geografia científica e acadêmica, legitimada, ao desconsiderar a docência da educação básica na sua autonomia profissional e intelectual.

D D Revista da Associação Nacional de Pós-graduação e Pesquisa em Geografia (Anpege).

D D p.175-195, V.15, n.28, set./dez. 2019. 
Além desses três motivos, poderíamos ainda adicionar um quarto, derivado direto não apenas da fragilidade acadêmica, mas também da construção das regras do jogo (Bourdieu, 2004) interno, porém, voltadas para demandas alheias. Sobre tais demandas, Paulo Rodrigues dos Santos observou os movimentos de construção das políticas, no final do século XX:

\footnotetext{
"A partir de meados da década de 1990, registra-se a presença crescente de políticas públicas mundiais no campo educacional brasileiro, que vêm legitimando formas e concepções educacionais que atravessam as diversas tendências presentes nas várias áreas disciplinares e alicerçam as bases hegemônicas do chamado 'pensamento único"'. (Santos, 2007, p. 363)
}

Vale lembrar que, passadas duas décadas, com a expansão da racionalidade neoliberal e a incorporação crescente do campo da educação como campo do mercado (Ball, 2014), não apenas as disciplinas escolares, mas também os campos científicos e acadêmicos são submetidos a fortes pressões externas.

\section{As armadilhas}

Para aprofundar o debate, retorno a um fato citado no início deste artigo. Em 2015, o Ministério da Educação (MEC) lançou a versão preliminar da BNCC. Desde então, essa política foi objeto de debates acalorados, inclusive no interior da academia. O conteúdo de história, por exemplo, foi motivo de tensões entre o campo e o MEC, ao passo que os representantes da sociologia e da filosofia se levantaram contra a redução ou ausência de espaço destinado a essas disciplinas no ensino médio. A BNCC é parte de um conjunto de ferramentas produzidas com o intuito de reestruturar a educação básica brasileira, em especial a educação pública. Fazem parte deste pacote, também, as avaliações externas e em larga escala (Prova Brasil, Exame Nacional de Ensino Médio, etc.), a Lei 13.415/17 (reforma do ensino médio), o Programa Nacional do Livro Didático ${ }^{3}$ (PNLD) e a Base Nacional Docente (BND).

A Lei 13.415/17 iniciou como Medida Provisória 746 (MP 746), em 22 de setembro de 2016, alterando a Lei de Diretrizes e Bases da Educação Nacional, oficialmente, em 17 de fevereiro de 2017. A soma da BNCC com a MP 746 (Lei 13.415/17) produziu agitação nos campos acadêmicos. Primeiro, porque definiu os conteúdos e a distribuição das disciplinas na educação básica. Depois, porque redefiniu relações entre as próprias disciplinas escolares e os seus recortes. História, filosofia, sociologia e geografia foram algumas disciplinas que protagonizaram protestos, tensões e disputas significativas, pois

3 O PNLD não é uma criação recente, mas é um importante instrumento de regulação da educação básica, que se incorpora aos demais. 
ficaram inscritas em uma mesma área do conhecimento, descaracterizadas em boa parte dos seus atributos conceituais e metodológicos. Contudo, especificamente para a geografia, essas duas políticas em especial levaram o subcampo para algumas armadilhas, colocando em xeque as suas próprias fragilidades.

Uma delas foi o impasse em torno da presença da geografia como componente curricular. Na verdade, essa foi uma dupla questão: a presença e o fato de se tornar um "componente curricular".

A BNCC, ainda em 2015, ao agrupar disciplinas tradicionais da cultura escolar brasileira em áreas do conhecimento, incidiu sobre as suas identidades, bem como sobre especificidades de cada uma delas. Ainda que inicialmente a organização por áreas tenha incorporado as disciplinas, o fato é que os pressupostos dos campos disciplinares foram desconsiderados. Seguiu-se, então, no campo da geografia e principalmente no subcampo de geografia-e-educação uma tensão sobre os rumos da geografia nas escolas. Agora, de maneira clara, uma geografia objeto, sem sujeito. Ignorado nas suas subjetividades, deslegitimado como intelectual e desqualificado como profissional, o professor de geografia agora se transformou em um executor, tanto por parte do Estado (e do mercado) quanto por parte da academia. Isso porque, para o primeiro, o projeto de educação massificada, padronizada, referendada e demandada pelo capital, reduz o trabalho docente ao de aplicação de conteúdos descritos em um documento curricular (BNCC e seus derivados regionais).

Ainda que as primeiras versões tivessem contado com a participação de professores da educação básica, essa pretensa participação foi na forma de contribuição limitada, não cabendo movimentos fora dos estipulados e muito menos a recusa ou discussão sobre seus fundamentos, como, por exemplo, a estruturação em competências e habilidades, ou as bases epistemológicas da geografia proposta. Além das consultas online, houve seminários regionais, que funcionaram mais como eventos de legitimação do que fórum de participação:

"O formato do seminário estadual [do Espírito Santo] não possibilitou as discussões, visto que, após as palestras, não foi aberto espaço para debate e, durante os grupos de trabalho, os professores deveriam seguir um modelo previamente elaborado para colocar suas proposições em um espaço de no máximo 300 caracteres". (Carvalho \& Lourenço, 2018)

Por sua vez, no subcampo geografia-e-educação foi tocado um lado sensível: o da hierarquia. Por extensão, também foi exposta a sua condição tributária ao campo da geografia. Por esses motivos, o subcampo, de maneira dominante, tendeu a concentrar o foco na defesa da permanência da geografia como conteúdo formal da educação básica, ao mesmo tempo que se engajou nas disputas pela definição de qual conteúdo deveria constar

D

D Revista da Associação Nacional de Pós-graduação e Pesquisa em Geografia (Anpege).

D D

p.175-195, V.15, n.28, set./dez. 2019. 
no documento. Apenas para citar um contraponto, a Associação Nacional de Pós-Graduação e Pesquisa em Educação (ANPEd), no início de 2016, como resposta à implementação da BNCC, lançou a campanha "Aqui já tem currículo". Na página eletrônica da Associação, assim apresentaram seu entendimento do processo e justificaram a chamada:

\begin{abstract}
“O MEC está elaborando a Base Nacional Comum (BNCC) que definirá o que deve ser ensinado nas escolas. Até o final do primeiro semestre de 2016 o Conselho Nacional de Educação receberá do MEC um texto da Base Curricular para discussão e homologação.
\end{abstract}

\begin{abstract}
Foram convidados especialistas para construir o texto da BNCC e criados espaços frios e pouco interativos para a participação de professores e estudantes. Consideramos que os professores e professoras de nossas escolas que já praticam currículos de variadas maneiras e com conteúdos plurais não foram devidamente ouvidos/as.
\end{abstract}

Por isso criamos a campanha Aqui já tem Currículo... para que possam circular por todo o Brasil vozes que narrem experiências curriculares já desenvolvidas. Vamos levar essas experiências de forma viva e criativa aos Conselheiros/as do Conselho Nacional de Educação". (ANPEd, 2016. Disponível em http:// www.anped.org.br/news/anped-lanca-campanha-aqui-ja-tem-curriculo-oque-criamos-na-escola, acessado em 12/07/2019)

Além da desconsideração dos professores no processo, ainda que por caminho diferente do MEC, a ausência de substratos teóricos para a discussão do contexto de maneira ampliada trouxe o subcampo para a arena de disputa curricular. Porém, com as regras e as armas que não tinha poderes para definir. Quer dizer, coube ao subcampo disputar internamente as lacunas restritas da tabela de conteúdos de geografia, mas não a inserção da ciência e nem mesmo o lugar dos professores no processo. Isso se deu, primeiro, pela desigualdade de forças entre os campos e o Estado. No caso, considerando o Estado como ponta de lança dos setores empresariais nacionais e internacionais. Depois, não houve reação porque não cabia uma disputa política mais abrangente e consistente, nem fazer disputas políticas sobre elementos os quais não havia debate prévio, ou elementos políticos que não eram motivos de preocupação até então.

Passou ao largo das discussões do subcampo a caracterização da geografia como "componente curricular" e não como disciplina, ou mesmo a forma tributária (novamente) dos conhecimentos e conteúdos de geografia em relação às competências e habilidades estipuladas para a disciplina.

A outra armadilha ficou por conta do isolamento do conteúdo em relação aos sujeitos, ratificando o conhecimento geográfico como objeto. Quando o contexto político criou uma encruzilhada entre um reordenamento dos agentes no subcampo (professores da educação 
básica e academia) e o aprofundamento das posições desses agentes, produziu-se, também, uma tensão interna. Afinal, as definições de conteúdos demandaram agentes que pudessem fazê-lo, incidindo sobre as práticas profissionais de professores da educação básica. Então, investida das hierarquias historicamente estabelecidas entre a geografia acadêmica e a geografia das escolas básicas, o alinhamento do subcampo com o Estado e o capital não chegam a ser uma surpresa. A armadilha está na possibilidade aberta de se definir o que vem a ser a geografia das escolas, uma vez que essa estará diretamente vinculada aos currículos de formação de professores, não só na BNCC, mas através da BND. Ou, seja, o subcampo terminou por contribuir para a restrição da sua própria atuação.

\section{A tentação}

As políticas chegaram trazendo armadilhas. Então, a despeito delas, os campos e subcampos foram obrigados a se movimentar, sob o risco de serem descaracterizados ou mesmo desaparecer. Afinal, a relação entre ciência e escola básica é muito mais complexa do que a suposição de repasses de conceitos ou traduções de um punhado de conteúdos. Há elementos importantes em jogo, como a difusão de conhecimentos científicos, a capilaridade das ciências na sociedade e a formação de quadros de pesquisadores potenciais, que muitas vezes são influenciados para a atividade científica a partir do contato com essa ou aquela disciplina, ainda na educação básica.

Não foi diferente com o campo da geografia, muito menos com o subcampo geografiae-educação. Mais especificamente, a vertente ensino de geografia (incluindo a educação geográfica), foi obrigada a incorporar debates diversos e se posicionar minimamente, ainda que isso não tivesse sido de forma coesa, internamente entre os seus agentes. $\mathrm{O}$ mais importante, diante das ameaças de redução ou de retirada da educação básica, foi mostrar-se em movimento, como uma prova de que existe vida, de que existe criação no subcampo e afirmar que a geografia na escola importa.

Contudo, nem só de armadilhas políticas se fez o processo. Além delas, em todas essas disputas, houve uma tentação difícil de ser ignorada e que aproveitou uma boa parte das fragilidades do subcampo: a definição.

Lembremos que a Base foi uma política definida no Plano Nacional de Educação, um ano antes, em 2014. Sua construção e implementação mobilizaram setores da comunidade acadêmica e da educação básica, em níveis de atuação variados e posições políticas distintas, disputando o processo. O que chamo de tentação para o subcampo consiste na possibilidade real de definir, em alguma medida, os rumos da geografia escolar, mediante a entrada nos

D 
processos oficiais, formais, de construção da BNCC. Ou seja, para agentes de um subcampo que se debruça sobre o que, por que e como ensinar, a real possibilidade de definir o objeto do seu trabalho é ao mesmo tempo uma tentação justificável pela natureza do ofício e compreensível pelas fragilidades anteriormente descritas.

Algo que nos remete à própria teoria de Bourdieu, quando se debruça sobre a estrutura dos campos e a distribuição do capital científico:

\footnotetext{
"Em outras palavras, os agentes (indivíduos ou instituições) caracterizados pelo volume do seu capital determinam a estrutura do campo em proporção ao seu peso, que depende do peso de todos os outros agentes, isso é, de todo o espaço. Mas, contrariamente, cada agente age sob a pressão da estrutura do espaço que se impõe a ele tanto mais brutalmente quando o seu peso relativo seja mais frágil”. (Bourdieu, 2004, p. 24)
}

A possibilidade de efetivamente definir o conhecimento de geografia a ser conteúdo obrigatório, legítimo e legal, para todas as escolas de educação básica do país, se converte em uma possibilidade, também, de redistribuição do capital político dentro do subcampo. Ainda que não seja consensual a legitimidade dessas demandas (principalmente dentro do subcampo), a incorporação das demandas externas por agentes internos não deve ser entendida apenas como opção individual. Significa que os agentes internos que as incorporam, independente da intensidade das pressões, não encontram resistências significativas dentro do campo, que sejam capazes de tensionar as escolhas individuais, em alguma medida.

Além disso, os processos de acumulação de capital científico e simbólico dentro deste subcampo frágil passa, também, pela capacidade de os agentes internos construírem articulações para fora, seja em outros campos científicos, seja em campos de outra ordem, como o econômico ou o político, que em alguma medida exercem pressão sobre ele.

Quanto mais se produz uma aproximação com as políticas de educação oficiais, em estreita vinculação com o Estado como regulador do campo educacional, mais se distancia politicamente dos professores, ainda que muitos pensem o contrário. Isso porque o objeto da aproximação são as políticas de regulação do trabalho docente: os conteúdos curriculares, os objetivos de aprendizagem, etc. Como foi dito anteriormente, a partir do momento em que os professores da educação básica tendem a ser desconsiderados como sujeitos dentro do subcampo e são reposicionados como objetos, a proposta de construção de uma Base para a educação básica chega como uma demanda que parece ser do subcampo, quando, na verdade, é uma demanda do Estado. No entanto, essa demanda encontra terreno fértil nas fragilidades do subcampo, o que faz com que aderir ao projeto de uma BNCC seja uma proposta tentadora. 
$\mathrm{Na}$ disputa constante pelas regras internas do subcampo, ter o poder de definir os pressupostos futuros de atuação é ao mesmo tempo motivo de reconhecimento e condição de acumulação de capital acadêmico. Chamo aqui de capital acadêmico, porque não se trata, como exemplificou Bourdieu, de uma intervenção científica com a capacidade de causar alterações nas relações e na estrutura do subcampo. A intervenção é acadêmica, com sentido político, considerando as redes de relações, os circuitos, os espaços de circulação, assim como as relações para fora do subcampo.

Nesse caso, então, a definição dos conhecimentos geográficos escritos e inscritos na BNCC são uma intervenção marcadamente política, capaz de redimensionar ou conservar o subcampo, mas não necessariamente uma intervenção científica, capaz de influenciar as relações ao redor e nos sistemas de referências na geografia ou na educação, por exemplo, como campos diretamente vinculados. Nesse caso, contraditoriamente, há um sério risco de o subcampo se reforçar como dependente e tributário da geografia, por exemplo, pela relação objetificada com o conhecimento geográfico.

Ou seja, mesmo quando pensamos na "defesa da geografia" em um currículo unificado e prescritivo, na verdade, o subcampo cumpre a tarefa que aparenta negar fazer: assume valores e serve ao sistema - desigual, antidemocrático, massificador, etc. - ao qual diz se opor. Reafirma a distância entre a universidade e a educação básica, quando indica aceitar assumir um papel de colaborador nas políticas de regulação do trabalho docente.

\section{Reflexões, caminhos e indícios}

A geografia é disciplina presente nos currículos escolares do Brasil desde o século XIX. Nas universidades brasileiras, a ciência geográfica tornou-se disciplina somente na década de 30 do século XX. Os caminhos dos dois campos ${ }^{4}$, desde então, têm sido marcados por aproximações, distanciamentos, sobreposições e conflitos. A mesma trajetória parece se reproduzir na interseção dos campos da geografia com a educação, que traz, em grande medida, resquícios da relação da universidade com as escolas. Essa zona de contato, tem sido uma área fértil de pesquisas e estudos, com abordagens, temáticas e recortes de objetos diferenciados. Indo desde as investigações sobre as dimensões espaciais do fenômeno educacional e educativo, até as discussões sobre o trabalho com o conhecimento geográfico nas escolas, esse subcampo geografia-e-educação recebe influências diversas, não apenas dos campos aos quais está diretamente relacionado, mas também de outros, aparentemente mais distantes, como o político e o econômico.

\footnotetext{
4 Nesse momento não importa o rigor no uso do conceito, como se deu ao longo deste texto, mas somente delimitar duas esferas de atuação, de demandas, de atribuições e, muitas vezes, de sujeitos.
}

D 
A implementação de uma política educacional por parte do Estado, nos moldes como vem acontecendo nos últimos anos, em especial no Brasil, incide diretamente sobre a estrutura do subcampo. As influências de outros campos e de agentes externos, em um subcampo marcado por fragilidades políticas, acadêmicas e científicas, tendem a ser mais intensas, em função da sua baixa capacidade de ser refratário aos apelos de demandas alheias (Bourdieu, 2004).

Em tempos de implementação de Base Nacional Comum Curricular e Lei de Reforma do Ensino Médio (Lei 13.415/17), as vertentes do subcampo que lidam mais diretamente com questões curriculares, metodológicas e pedagógicas são mobilizadas a assumir posições, não apenas dentro deste, mas também em relação aos agentes que exercem as pressões e também para a sociedade. Nesse momento, tornam-se mais explícitas as dinâmicas internas do subcampo. Os agentes, nos movimentos de tomadas de posição, produzem discursos e mobilizam seu capital político e acadêmico no jogo das regras internas, disputando o ordenamento e as inclinações do próprio subcampo.

Tais movimentos, contudo, não se dão sem contradições - algumas já presentes na estrutura do subcampo, outras, derivadas das condições que são apresentadas. É o que acontece na implementação de uma base curricular que se pretende nacional e comum. Discursos de "defesa da geografia" são proferidos de forma tão veemente quanto vaga, pois não se apresenta o que é, nem como, muito menos o que significa a presença da geografia nas escolas, a partir de um documento legal, com função de instrumento de regulação do trabalho docente.

Com relação ao sistema educacional, a reprodução dos valores dominantes se dá de forma mais complexa do que as ações diretas conseguem dar conta. A implementação de políticas acontece a partir de marcos legais, mas também são resultados de processos anteriores e que continuam a acontecer, mesmo depois da implementação das leis. Isso significa que o sucesso da implementação das políticas não deve ser medido necessariamente pelas formas e resultados esperados, mas pelos efeitos que produzem naquilo que se propõem e também pela abrangência das mudanças (ou conservação) que mobiliza. $O$ caso da vertente do ensino de geografia, no curso da implementação da Base é emblemático nesse sentido.

As diversas formas de adesão e distanciamento da política oficial mostram como o subcampo foi se movendo ao sabor da conjuntura, sem buscar, necessariamente, tensionála. Agentes diversos assumiram papeis distintos, seja atuando na sua elaboração ou na implementação, em vários momentos e de formas distintas, com maior ou menor grau de entendimento e de adesão aos propósitos das políticas. Independente das motivações 
alegadas pelos agentes, o fato é que a BNCC é um instrumento legal de regulação do trabalho docente, assim como a Lei 13.415/17 regula tanto a estrutura organizativa das escolas e do trabalho com o conhecimento quanto a docência, inclusive nas suas atribuições.

Nesse processo de elaboração, implementação e execução das políticas, o campo foi tensionado em questões da sua estrutura. As suas aproximações, sua autonomia, suas vinculações acadêmicas e científicas, enfim, sua autonomia e sua economia interna foram diretamente tocada pelas transformações pelas quais estavam passando os seus objetos e sujeitos: professores e escolas. A opção dominante, ou seja, dos agentes internos dotados de maior capital acadêmico e político, tem sido inegavelmente concordante com as políticas. Isso porque a tentação não resistida de definir os rumos da geografia nas escolas em nível nacional marcou uma tomada de direção no sentido da academia e das estruturas dominantes, e não da defesa da autonomia docente, ou do trabalho docente como atividade intelectual, de fato.

O preço da liberdade do campo e dos agentes do campo, então, é capitalizado pela liberdade de fazer o sistema funcionar da forma como é pretendido pelos grupos dominantes - que estão nas esferas de decisão do Estado, por exemplo, elaborando e cuidando da implementação das políticas. Longe de ser uma opção de resistência ou "re-existência", no sentido dos debates decoloniais, trata-se mais de uma adaptação do subcampo e dos seus agentes aos "novos tempos", às "novas demandas", aprofundando a posição de professores da educação básica e das escolas como seus objetos. A tomada de direção não é nova, mas é ratificada no atual contexto. É uma tomada de posição que ratifica, também, o subcampo como tributário e instrumental de demandas de outros campos.

Essa análise leva em conta o momento atual e os processos que vêm construindo o atual contexto. Leva em conta, também, que a história é dinâmica e é processo, construída nos conflitos e negociações, nas correlações de forças que nem sempre resultam em cenários previsíveis. São aproximadamente 2,5 milhões de docentes, no Brasil. É importante levarmos em conta que não se pode falar de uma massa passiva, de mero receptáculo de demandas e executora de comandos superiores. Por essa razão, há em curso uma série de medidas oficiais e não oficiais - de desautorização do trabalho docente, via desqualificação da atividade e da sua descaracterização como profissão. Uma dessas medidas consiste na elaboração de "conteúdos a serem ensinados" pelos professores, nas escolas - entendidos como executores, com desejáveis habilidades criativas, mas desconsiderados como intelectuais.

D D Devista da Associação Nacional de Pós-graduação e Pesquisa em Geografia (Anpege).

D D p.175-195, V.15, n.28, set./dez. 2019. 
O subcampo, a partir do ensino de geografia, pela sua natureza, carrega o conflito permanente da definição de posição. Uma vez alojado em grupos de pesquisa e departamentos de universidades, traz em si as marcas das relações históricas entre universidade e escola básica, no Brasil. Mover-se em sentido diferente deste é fazer um movimento que rompe com uma cultura hierarquizante e hierarquizadora, tanto de sujeitos e instituições, quanto de saberes. Deriva daí a adesão às políticas de currículo sem a devida criticidade, sem considerar a dimensão profundamente reguladora do trabalho docente nelas inscritas.

A força das mudanças impostas, contudo, carrega em si as suas contradições e as dos processos. É possível que as pressões de desregulação do trabalho docente e o esvaziamento da escola como espaço de construção de conhecimento desague no esvaziamento de sentidos da própria vertente do ensino de geografia e do subcampo, como consequência da tensão provocada. O fenômeno, já em curso, coloca o subcampo diante de dois caminhos mais evidentes.

O primeiro, assume a condição uma não-ciência subalterna, dependente e derivada de conceitos, concepções e métodos de outros campos, reduzida ao papel instrumental, mesmo que travestida de ciência. Não é muito diferente dos caminhos que historicamente têm sido tomados, mas, agora, incorpora os projetos dominantes de maneira mais explícita.

No segundo, contudo, há riscos: distanciar-se do conforto subserviente dos campos acadêmicos de referência (educação e geografia), produzindo referenciais e abordagens próprias, em articulação direta com professores de geografia da educação básica. É uma opção pela defesa do cotidiano da escola como lugar de produção de conhecimentos, defesa da docência como atividade intelectual e da superação de uma cultura acadêmica que hierarquiza saberes, subalterniza sujeitos e fragiliza um campo potente. 


\section{Referências}

1. BALL, Stephen J. Educação global S. A.: novas redes de políticas e o imaginário neoliberal. Ponta Grossa: UEPG, 2014.

2. BOURDIEU, Pierre. Os usos sociais das ciências - por uma sociologia clínica do campo científico. São Paulo: UNESP, 2004.

3. BOURDIEU, Pierre. O poder simbólico. Rio de Janeiro: Editora Bertrand Brasil, 1989.

4. BOURDIEU, Pierre, Economia das trocas simbólicas. São Paulo: Editora Perspectiva, 1987.

5. BRASIL. Ministério da Educação. Base Nacional Comum Curricular. Disponível em http:// basenacionalcomum.mec.gov.br, 2016. Acesso em 10 de julho de 2019.

6. BRASIL. Lei $\mathbf{n}^{\mathbf{0}} \mathbf{1 3 . 4 1 5}$, de 16 de fevereiro de 2017. Altera as Leis nos 9.394, de 20 de dezembro de 1996, que estabelece as diretrizes e bases da educação nacional, e 11.494, de 20 de junho 2007, que regulamenta o Fundo de Manutenção e Desenvolvimento da Educação Básica e de Valorização dos Profissionais da Educação, a Consolidação das Leis do Trabalho - CLT, aprovada pelo Decreto-Lei no 5.452, de 1 o de maio de 1943 , e o Decreto-Lei no 236, de 28 de fevereiro de 1967; revoga a Lei no 11.161, de 5 de agosto de 2005; e institui a Política de Fomento à Implementação de Escolas de Ensino Médio em Tempo Integral. Brasília, fev. 2017. Disponível em: <www.planalto.gov.br/ ccivil_03/_ato2015-2018/2017/lei/L13415.htm>. Acesso em: 10 de julho de 2019.

7. CARVALHO, Janete Magalhães \& LOURENÇO, Suzany Goulart. O silêncio de professores da educação básica pela estratégia de fazê-los falar. In Pro-posições. Campinas: Unicamp. Vol. 29, n. 2 (87), maio/agosto, 2018.

8. CALLAI, Helena Copetti \& MORAES, Maristela Maria. Educação geográfica, cidadania e cidade. ACTA Geográfica, Boa Vista, Edição Especial, 2017, p. 82-100.

9. GONÇALVES, Amanda Regina. A geografia escolar como campo de investigação: história da disciplina e cultura escolar. In Revista Bibliográfica de Geografia y Ciencias Sociales. Barcelona: Universidade de Barcelona. Vol. XVI, n. 905, 15 de enero de 2011. Versão online, disponível em <http://www.ub.edu/geocrit/b3w-905.htm\#_edn9>, acessado em 10 de julho de 2019.

10. HATO, Júlio Takahiro. Geografia da educação. 2010. 141 f. (Mestrado em Geografia). Faculdade de Filosofia, Letras e Ciências Humanas, Universidade de São Paulo, São Paulo, 2010.

D 
11. INEP - Instituto Nacional de Estudos e Pesquisas Educacionais Anísio Teixeira. Geografia da educação brasileira. Brasília: O Instituto, 2000.

12. SANTOS, Paulo Rodrigues dos. Entre o ensino de geografia e a geografia escolar: reflexões críticas. In TRINDADE, G. A. \& CHIAPETTI, R. J. N. (Org.). Discutindo a geografia: razões para se (re)pensar a formação do professor. Ilhéus: Editus, 2007. 